\title{
Frezlerle ve sonik uçlarla basamaklı kole preparasyonu yapılmış dişlerin yüzey pürüzlülüğünün karşılaştırmalı olarak araştırılması
}

\author{
Ece Tamaç(0000-0003-0475-3205) ${ }^{\alpha}$, Muhittin Toman(0000-0002-4221-5670) ${ }^{\alpha}$, Suna Toksavul(0000-0002-8780-0048) ${ }^{\alpha}$
}

Selcuk Dent J, 2020; 7: 66-71 (Doi: 10.15311/selcukdentj.434574)

Başvuru Tarihi: 18 Haziran 2018 Yayına Kabul Tarihi: 08 Ocak 2019

\section{öz}

Frezlerle ve sonik uçlarla basamaklı kole preparasyonu yapıImış dişlerin yüzey pürüzlülüğünün karşılaştırmalı olarak araştırılması

Amaç: $\mathrm{Bu}$ in vitro çalışmanın amacı, döner aletlerde kullanılan normal gren boyutlu elmas frezlerle prepare edilen dişlerin yüzey pürüzlülüğünün, döner aletlerde kullanılan normal gren boyutlu elmas frezlerle birlikte özel ultra sonik uçlar kullanılarak prepare edilen dişlerin yüzey pürüzlülüğü ile karşılaştırmaktır.

Gereç ve Yöntemler: 20 adet yeni çekilmiş, çürüksüz molar diş bu çalışma için seçilerek döner aletlerde kullanılan normal gren boyutlu elmas frezlerle prepare edilmiştir. Bu dişlerin içinden 10 tanesi seçilerek bu dişlerin preparasyonları özel ultrasonik uçlarla bitirilmiş ve böylece ikinci bir grup oluşturulmuştur. Bu işlemlerin ardından yüzey pürüzlülüğünün kaydı yapıImıştır. Yüzey pürüzlüğü Ra (yüzey profilinin aritmetik ortalaması) ve Rz (yüzey pürüzlülük profilinin en yüksek beş noktası ve en düşük beş noktası arasındaki dikey mesafe) gibi farklı parametreler kullanılarak değerlendirilmiştir.

Bulgular: Ra parametre değerlerine göre, döner aletlerde kullanılan normal gren boyutlu elmas frezlerle prepare edilen grup dişlerin yüzey pürüzlülüğü, sonik aletlerle preparasyonu düzeltilen gruba göre istatistiksel olarak daha yüksek bulunmuştur $(p=0.002) . R z$ parametre değerlerine göre ise, bu iki grubun yüzey pürüzlülük değerleri arasında istatiksel olarak anlamlı bulunmamıştı $(p>0.05)$.

Sonuç: Bu çalışmanın sınırları dahilinde diş preparasyonunun özel ultrasonik uçlarla bitirilmesinin daha pürüzsüz diş yüzeylerinin elde edilmesinde etkili olduğu tespit edilmiştir. Daha pürüzsüz bir diş prepararasyonu ise üretilecek olan restorasyonların daha başarı ı marjinal ve internal uyumlarının yanı sıra adeziv simantasyon başarısını da arttıracaktır.

\section{ANAHTAR KELIMELER}

Dental aletler, diş preparasyonu, ultrasonikler

Sonik ve ultrasonik sistemlerin diş hekimliğinde kullanımı ilk olarak 1957 yılında kök kanal preparasyonu ile başlamıştır. Daha sonra kavite preparasyonunda, periodontal tedavi işlemlerinde kullanılmaya başlanmıştır. Son yıllarda, dişlerin preparasyonunda kullanılan konvansiyonel döner aletlere alternatif olarak sonik uçlar kullanılmaktadır.

Günümüzde sabit protetik restorasyonlarda diş kesimi yapılırken daha pürüzsüz bir bitim sınırı ve diş yüzeyi

\section{ABSTRACT}

A comparison of surface roughness of dentin after tooth preparation with conventional rotary and ultrasonic instrumentations

Background: The aim of this in vitro study was to compare the surface roughness of tooth preparations finished with only using rotary instruments and finished with rotary instruments + an ultrasonic generating device.

Methods: Twenty extracted, caries free, human molars preparations were performed using rotary intruments with regular grit diamond burs. 10 of these prepared teeth were selected and their preparations finished with diamond tips held in an ultrasonic generating device. The surface roughness of prepared teeth was recorded. The surface roughness was evaluated using different parameters like $\mathrm{Ra}$ (arithmetic mean deviation of the roughness profile) and $\mathrm{Rz}$ (the average distance between the five highest peaks and five deepest valleys within the sampling length).

Results: According to Ra parameter data, the surface roughness of teeth prepared with only regular grit diamond burs using rotary instruments was statistically higher than those of teeth prepared with regular grit diamond burs using rotary instruments + diamond tips held in an ultrasonic generating device $(p=0.002)$. According to $R z$ parameter data, there was not significantly difference between the surface roughness of these two groups ( $p>0.05$ ).

Conclusion: Within the limitations of this study, using the diamond tips held in ultrasonic generating device for finishing the tooth preparation is an effective method to reach smoother surfaces. Smoother preparation surfaces makes marginal and internal gaps smaller of the restorations will be fabricated and also increases the success of adhesive cementation.

\section{KEYWORDS}

Dental instruments, tooth preparation, utrasonics

hazırlamak için sonik enerjiyle çalışan özel uçlar (Sonic prep- KaVo, Almanya) geliştirilmiştir. Bu uçlar, $6.5 \mathrm{kHz}$ sonik frekans ve 3-3.5 bar basınçla çalışan bir hava türbininin (Sonicflex 2000N, KaVo, Almanya) ucuna takılarak aktive edilmektedirler. ${ }^{1,2}$ Bu sistem değişik amaçlarla kullanılan farkı uçlara sahiptir (sonicflex micro invaziv, sonicflex endo, sonicflex retro, sonicflex prep). Diş kesiminde kullanılan sonicflex prep uçların yüzeyi $25 \mu \mathrm{m}$ boyutunda elmas partiküllerle kaplıdır. Sonicflex

\footnotetext{
${ }^{\alpha}$ Ege Üniversitesi Dişhekimliği Fakültesi Protetik Diş Tedavisi Anabilimdalı, İzmir
} 
prep vario 60 uçlar, adeziv inley kavitelerin aproksimal yüzeylerinin bitirilmesi işleminde kullanılabilir. Komşu dişe zarar vermeden ideal bir marjin preparasyonu elde edilir. Sonicflex prep vario 45 uç ile ise inley ve parsiyel kronlar için kavite hazırlanmasında ideal açılara sahip belirgin bevelların oluşturulması sağlanır. Bu uçlar titreşimle çalıştığı için dişetine ve komşu dişlere zarar vermez, atravmatik çalışma sağlayarak pulpada geri dönüşümsüz hasarlara neden olmaz. Günümüzde elmas, tungsten karbit, çelik ve tungsten carbid bitirme frezleri preparasyon sırasında kullanılan frezlerdir. Elmas frezlerde partikül büyüklüğü diş yüzeyinde oluşan ISı oluşumu dolayısıyla pulpal hasar üzerinde etkilidir. Kalın grenli elmas frezlerin diş preparasyonu sırasında pulpa odasında daha belirgin ISı artışına neden olduğu bildirilmiştir. ${ }^{3}$ Tungsten karbit frezlerin ise elmas frezlere göre pulpa odasında daha az basınç ve sıcaklık değişikliğine neden olduğu gösterilmiştir. ${ }^{4}$ Vanderlei ve ark. ${ }^{5}$ yaptıkları çalışmada sonik uçlar ile yapılan preparasyon sırasında oluşan ısı artışının pulpa hasarına neden olacak seviyede olmadığını bildirmiştir. Anterior dişlere uygulanan estetik restorasyonlarda bir miktar dişetinin altına inmek gerekir, titreşimle çalışan sonik uçlar ile dişetine zarar vermeden düzgün bir subgingival bitiş sınırı hazırlanabilir.

Sabit protetik restorasyonlarda en sık karşılaşılan sorun sekonder çürük oluşumudur. ${ }^{6}$ Kron veya köprülerin marjinal adaptasyonunun iyi olmaması sonucu marjinal sızıntı ve dolayısıyla çürüklere neden olmaktadır. Bu yüzden düzgün ve pürüzsüz bir marjinal bitiş sınırı hazırlamak çok önemlidir. Diş kesimi yapılırken ilk önce konvansiyonel döner aletler ile sert olan mine dokusu kaldırıldıktan sonra son düzeltmelerin sonik uçlarla yapılması ile pürüzsüz bir yüzey ve düzgün marjinal bitiş sınırı hazırlanabilir böylece daha iyi ve net bir ölçü alınması ile marjinal uyumu çok iyi olan restorasyonlar hazırlanabilir.

Protetik restorasyon yapımının ilk basamağı dişlerin preparasyonudur. Genelde elmas kaplı fisür frezler kullanılmaktadır. Elmas partikülleri diş sert dokusunu kolaylıkla uzaklaştırırken diş yüzeyinde pürüzlü bir yüzey oluşturmaktadır. Bu pürüzlü yüzey eskiden kullanılan konvansiyonel simanlar için mikromekanik bir bağlantı sağlarken günümüzde kullanılan adeziv simantasyon için bir dezavantaj oluşturmaktadır. Estetik beklentinin artması tüm seramik restorasyonların gelişmesinde önemli rol oynamıştır. Tüm seramik restorasyonların simantasyonunda kullanılan adeziv simantasyon sistemlerinde kompozit rezin siman hem diş hem de restorasyon iç yüzeyine adezyon ile tutunmaktadır böylece tüm seramik restorasyonların mikrosızıntısı konvansiyonel simanlara göre önemli derecede azalmaktadır : ${ }^{7,8}$ Kompozit kimyasal olarak en azından iki farklı materyalin; monomer ve inorganik doldurucunun kombinasyonudur ve yapıyı oluşturan materyallerin tek başlarına göstermedikleri özelliklere sahiptir. Monomer ve doldurucu arasındaki kimyasal bağlantı $\gamma$-metakriloksipropil trimetoksisilan denilen organik silanize edici bir ajan tarafından sağlanır. ${ }^{9}$ Kompozit rezin esaslı yapıştırma simanları, büyük ölçüde doldurucu içeren BIS-GMA rezin ve bu rezinin içine ilave edilen ve karışımın pasta veya likit şeklinde kullanımını sağlayan diğer metakrilatların (TEDGMA, UDMA) varyasyonları şeklinde bulunurlar. ${ }^{10}$ Kompozit rezin esaslı yapıştırma simanlarında dahil olmak üzere tüm kompozitlerin mekanik özellikleri kullanılan bu maddelerle doğrudan ilişkilidir. Polimerizasyon reaksiyonu temelde 3 aşamadan oluşur; başlangıç, ilerleme ve bitim. Reaksiyon; Isı, UV ışık ve peroksitler ile hızlandırılabilir. Her durumda reaksiyon; ISI, kimyasal veya fotokimyasal reaksiyonlarla oluşturulabilen serbest radikallerin açığa çıkarılması ile başlar. Serbest radikaller monomer molekülündeki doymamış çift bağı açarak molekülü aktive eder diğer monomerlerle birleşerek polimer zincirleri oluşturur. Bu işlem ortamda serbest radikal kalmayana kadar devam eder. ${ }^{11}$ Oksijen varlığında serbest radikaller oksijenle reaksiyona girmeye eğilimli olduğundan, bu radikaller oksijenle reaksiyona girerek reaktif olmayan peroksi radikalleri oluştururlar ve oksijenle temas eden yüzeylerde polimerizasyon tam olarak gerçekleşmez. Bu olaya 'polimerizasyonun oksijen tarafından inhibisyonu', yüzeyde oluşan tabakaya da 'oksijen inhibisyon tabakası' adı verilmektedir. ${ }^{12}$ Diş yüzeyinde girintili çıkıntılı bir yüzey oluştuğu zaman girintili alanlara oksijen hapsolmakta ve polimerizasyonu engellemektedir. Bu nedenle adeziv simantasyon öncesinde diş yüzeyinin mümkün olduğunca pürüzsüz olmasını sağlamamız gerekmektedir. Bu noktada sonik cihazların kullanımı önemli bir avataj sağlar. Bu in vitro çalışmanın amacı, sadece döner aletlerde kullanılan normal gren boyutlu elmas frezlerle prepare edilen dişlerin yüzey pürüzlülüğü ile döner aletlerde kullanılan normal gren boyutlu elmas frezler + özel ultra sonik uçlar kullanılarak prepare edilen dişlerin yüzey pürüzlülüğünü karşılaştırmaktır.

\section{GEREÇ VE YÖNTEM}

Çalışmada periodontal veya protetik nedenlerle çekilmiş çürüksüz 20 adet alt veya üst azı dişi kullanıldı. Dişlerin üzerinde bulunan yumuşak doku artıkları keskin uçlu ekskavatörle temizlendikten sonra yüzeydeki renklenmeler uzaklaştırıldı ve dişler her birinde 10'ar adet olmak üzere rastgele iki gruba (Grup 1 ve Grup 2) ayrıldı. Ardından dişler C tipi koyu kıvamlı silikon ölçü malzemesi (Coltene, Speedex putty, Coltène/Whaledent AG, Altstätten, Switzerland) içerisine mine sement sınırından 2 mm. aşağıda olacak şekilde gömüldü (Resim 1). Dişlerin silikon ölçü maddesi içerisine yerleştirilmesi kök yüzeyinde periodontal ligament etkisi yaratarak hafif diş mobilitesine izin vermekte ve sonik enerjinin bir kısmını absorbe ederek bu 
bu uçların klinik kullanımını taklit etmektedir. Grup 1 ve 2'deki dişlerin bukkal yüzeyleri, aerator ucuna takılan, dönerek çalışan yeşil kuşak elmas frez ile su soğutması altında beş sefer gidip gelecek şekilde prepare edildi ve düz bir yüzey oluşturuldu (Resim 2) (Tablo 1). Daha sonra grup 2' deki dişlerin prepare edilen aynı yüzeyinden havalı scaler (KaVo SONicflex airscaler, KaVo Dental GmbH, Biberach, Germany) ucuna takılan sonik uçlar ile beş sefer geçildi (Resim 3). Her iki gruptaki prepare edilen alanlar yuvarlak içine alınarak taranacak alanlar belirlendi. Her bir dişin yuvarlak içine alınan bölgesinden üç farklı noktadan olmak üzere yüzey pürüzlülük ölçüm cihazı (Surftest SJ-301, Mitutoyo, Tokyo, Japan) ile ölçümler yapıldı. Ölçüm yapılan her bir nokta $0.8 \mathrm{~mm}$ lik alanı taradı. Her bir noktanın $\mathrm{Ra}, \mathrm{Rz}, \mathrm{Rq}$ değerleri elde edildi. Elde edilen sonuçlar istatiksel olarak değerlendirildi.

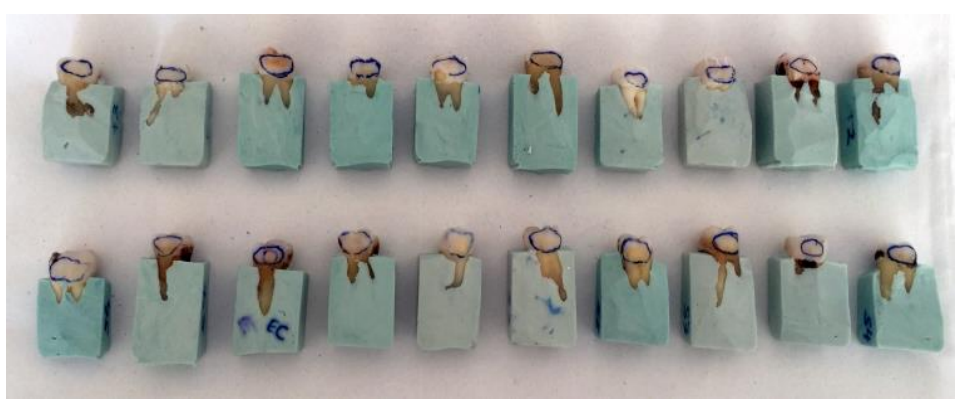

Resim 1.

Preparasyon için hazırlanan diş örnekleri

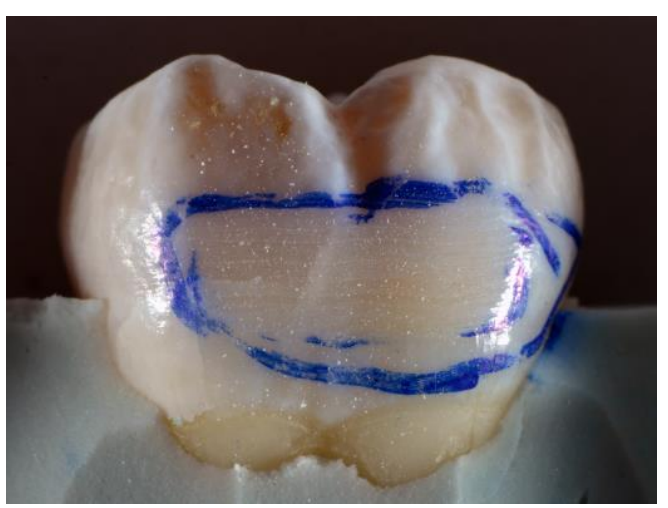

Resim 2.

Döner aletlerde kullanılan yeşil kuşak elmas frezlerle yüzey pürüzlendirilmesi yapılan diş örneği (Grup 1)

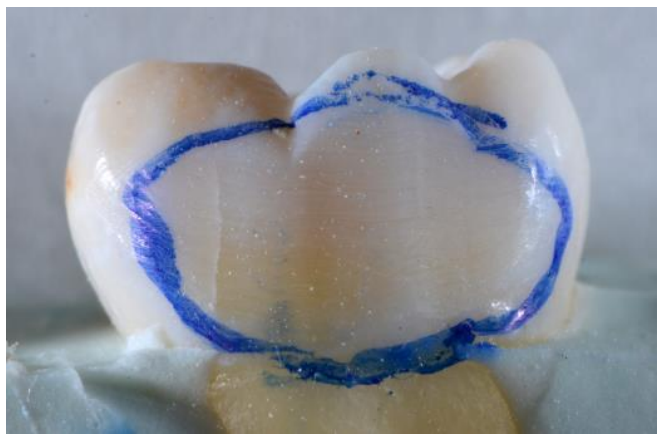

Resim 3.

Döner aletlerde kullanılan yeşil kuşak elmas frezler + sonik enerjiyle çalışan özel uçlarla yüzey pürüzlendirilmesi yapılan diş örneği (Grup 2)
Tablo 1.

\section{Her iki gruptaki dişler için uygulanan preparasyon yöntemleri}

\begin{tabular}{|ll}
\hline Grup 1 & $\begin{array}{l}\text { Döner aletlerde kullanılan elmas frezlerle } \\
\text { preparasyon }\end{array}$ \\
\hline Grup 2 & $\begin{array}{l}\text { Döner aletlerde kullanılan elmas frezler }+ \\
\text { sonik aletlerde kullanılan özel uçlarla } \\
\text { preparasyon }\end{array}$ \\
\hline
\end{tabular}

\section{Yüzey pürüzlülüğü ölçümü}

Yüzey pürüzlülük ölçümünde iğneli tarama metodu ile yüzey pürüzlülüğü ölçen Mitutoya Surftest SJ-301 cihaz kullanılmıştır. Kullanılan yüzey pürüzlülük cihazının ölçme hızı $0.5 \mathrm{~mm} / \mathrm{sn}$, ölçülen her bir noktanın alanı $0.8 \mathrm{~mm}$ dir. Her bir dişin yuvarlak içine alınan bölgesinden 3 farklı noktadan olmak üzere birinci grupta 30 ölçüm, ikinci grupta 30 ölçüm ve toplamda 60 noktadan ölçüm yapıldı.

Yapılan ölçümler sonucunda Ra, Rz, Rq değerleri elde edildi. Yüzey pürüzlülüğü ölçüm parametrelerinden iki tanesi seçildi: her bir noktanın artimetik ortalama değeri $(\mathrm{Ra})$ ve her bir noktanın en düşük ve en yüksek pik noktaları arasını ölçen (Rz) değerleri seçildi.

Diş yüzeylerinden her bir grup için ölçülen Ra ve $R z$ değerleri ortalamaları alındıktan sonra Ege Üniversitesi Tıp Fakültesi Biyoistatistik Bölümü'nde SPSS 21.0 (SPSS Inc., Chicago, IL, USA) istatistik programı kullanılarak istatistiksel değerlendirilmesi yapıldı.

Normal dağılımı kontrol etmek için, tüm veriler üzerinde Kolmogorov-Smirnov testi kullanıldı $(\alpha=0.05)$. Varyansların homojen olup olmadıkları Levene testi ile analiz edildi. Çıkan sonuçlar doğrultusunda veriler, gruplar arasında istatiksel olarak anlamlı bir fark olup olmadığını belirlemek için bağımsız iki örnek T-testi testleri ile SPSS 21.0 (SPSS Inc., Chicago, IL, USA) programı kullanılarak değerlendirildi.

\section{BULGULAR}

Çalışmada sadece döner aletlerde kullanılan elmas frezler (Grup 1) ve döner aletlerde kullanılan elmas frezler + sonik aletlerde kullanılan özel uçlarla (Grup 2) aşındırılan diş yüzeylerinin yüzey pürüzlülüklerinin $R a$ ve $R z$ yüzey pürüzlülük parametrelerine göre elde edilen ortalama ve standart sapma değerleri Tablo 2'de verilmiştir. Varyansların homojenliği dikkate alınarak, Ra değerleri için bağımsız iki örnek Ttesti yapıldığında iki grup arasındaki fark istatistiksel olarak anlamlı bulunmuştur $(p=0.002)$. Rz değerleri için de bağımsız iki örnek T-testi yapıldığında iki grup arasındaki fark istatiksel olarak anlamlı bulunmamıştır $(p>0.05)$. 
Tablo 2.

\section{Her iki grup için elde edilen Ra ve $\mathbf{R z}$ parametrelerinin ortalama değerleri ve standart sapmaları}

\begin{tabular}{c|ccc|} 
& & $\begin{array}{c}\text { Ortalama } \\
(\boldsymbol{\mu m})\end{array}$ & $\begin{array}{c}\text { Standart } \\
\text { Sapma }\end{array}$ \\
\hline \multirow{2}{*}{$\mathbf{R a}$} & Grup 1 & 6.07 & 1.19 \\
\cline { 2 - 4 } & Grup 2 & 4.32 & 0.97 \\
\hline \multirow{2}{*}{$\mathbf{R z}$} & Grup 1 & 31.9 & 6.55 \\
\hline & Grup 2 & 25.67 & 5.6 \\
\hline
\end{tabular}

\section{TARTIŞMA}

Sabit protetik restorasyonlarda daha başarılı kenar uyumu ve adeziv simantasyonun sağlanabilmesi için yapılan diş preparasyonu işleminin önemi oldukça büyüktür. Diş preparasyonunda daha pürüzsüz dentin yüzeyi oluşturabilmek için birçok enstruman ve preparasyon yöntemi geliştirilmiştir. Daha pürüzsüz dentin yüzeyi oluşturabilmek için diş preparasyonuna öncelikle kaba grenli enstrumanlarla başlanıp ardından kullanılan enstrumanların gren boyutları kademeli olarak azaltılarak preparasyona devam edilmelidir. Önceki çalışmalarda özellikle basamak bölgesinin preparasyonunda döner aletlerle birlikte kullanılan gren boyutları ortalama $100 \mu \mathrm{m}$ olan normal gren boyutlu elmas frezlerin yeterince pürüzsüz dentin yüzeyi oluşturamadığı belirtilmiştir. ${ }^{13}$ Diş preparasyonunda daha pürüzsüz dentin yüzeyi oluşturabilmek için döner aletlerle birlikte kullanılan gren boyutları ortalama $60 \mu \mathrm{m}$ ve $25 \mu \mathrm{m}$ olan ince ve süperince gren boyutlu elmas frezler geliştirilmiştir. Elmas frezlerin dişında döner aletlerle birlikte kullanılan 8, 12, 16 ve 30 yivli karbid frezler de bulunmaktadır. Araştırmacılar 30 yivli karbid frezlerin, 12 yivli karbid ya da ince ve superince gren boyutlu elmas frezlere göre daha pürüzsüz bir dentin yüzeyi oluşturabildiğini belirtmişlerdir. ${ }^{14}$ Ayrıca bunların dışında mine keskileri gibi el aletleri ve sonik enerjiyle çalışan aletlerle kullanılan özel elmas uçlar da dentin yüzeyinin pürüzsüz hale getirilmesi için geliştirilmiş özel enstrumanlardır. Geliştirilen tüm bu enstrumanlar arasından bu in vitro çalışmada ince ve süperince gren boyutlarına sahip elmas frezler ve özel ultrasonik uçlarla oluşturulan dentin yüzeylerinin pürüzlülüğü karşılaştırılmıştır.

Yüzey pürüzlülüğünün araştııılığı önceki çalışmalarda özellikle kullanılan frezlerin gren boyutlarının yanısıra kullanılan yüzlerinin de etkili olduğu belirtilmiştir. Frezlerin yan yüzleri kullanıldığında normal gren boyutlu frezlerle oluşturulan dentin yüzeyinin pürüzlülüğü (Ra) $9.3 \mu \mathrm{m}$, ince grenli frezlerle $3.1 \mu \mathrm{m}$, süperince grenli frezlerle ise 2.7 $\mu \mathrm{m}$ olarak bulunmuştur. Ancak özellikle basamak bölgesindeki diş preparasyonunda olduğu gibi frezlerin uç kısmıla yapılan preparasyonlarda, elmas frezlerin tepesindeki elmas grenlerinin gren boyutlarından bağımsız olarak dönme hareketi nedeniyle yüzeyde oluşan çıkıntılı alanları ezerek daha düzgün bir yüzey oluştuğu görülmüştür (Ra 1.02-1.12 $\mu \mathrm{m}){ }^{14,15}$ Çalışmamızda da frezlerin yan yüzeyleri kullanılmıştır. Bu nedenle kullanılan elmas frezlerin gren boyutunun sonuçlar üzerinde daha etkili olduğu düşünülmektedir.

Kullanılan aletlerin hızı, kesici uçların cinsine bağlı olarak, preparasyon sırasında fiziksel, kimyasal ve ısıl faktörler, kesici uçlar ve kesilen diş yüzeyi arasındaki mekanik hareketlerin de etkisiyle diş yüzeyinde bazı izler olusur. Nominal yüzey çizgisinin altında ve üstünde düzensiz sapmalar meydana getiren bu duruma yüzey pürüzluilüğü denir. Kullanılan aletlerin kesme hızı, yüzeyde ilerlemesi ve oluşan dentin talaşlarının derinliği gibi kesim işlemini kontrol eden faktörler üst seviyede kontrol edilebilir. Kesici uçların ilerleme veya kesim hızı gibi işlem parametrelerinin uyumunu değerlendirmek istenilen yüzey pürüzlülüğünün elde edilmesini sağlar. Bir talaşlı işleme tipi olan elmas frezlerin döner aletlerle kullanılması işlemiyle genellikle yüksek kesme hızında daha iyi yüzey kalitesi elde edilir. Ancak yüksek kesme hızı kullanılan frezlerin körelmesini hızlandırdığı için aynı yüzey kalitesi uzun süre muhafaza edilemez. Bunun yanı sıra kullanılan aletlerin oluşturduğu titreşimler nedeniyle diş yüzeyinde meydana gelen düzensiz çiziklerin yüzey pürüzlülüğü üzerinde olumsuz etkisi bulunmaktadır.

Yüzey pürüzlülüğünü değerlendirmek amacıyla pek çok cihaz ve teknik kullanılmaktadır. Bunlar arasından temas uçlu (iğneli) ve 3D ışık-optik ölçüm sistemleri en sık kullanılan yöntemlerdir. Bu çalışmada kullanılan temas uçlu ölçüm sisteminde, dedektör sürücü ünitesine bağlıdır. Bir motor yardımıyla yatay olarak yüzey üzerinde ileri geri hareketini yapar. Dedektörün yüzey üzerindeki yatay hareketi sırasında yüzey üzerindeki pürüzlere değen dedektöre bağlı elmas uçlu iğnenin dikey hareketinin oluşturduğu mekanik sapmaların sürücü ünitesi tarafından elektrik sinyallerine çevrilip yükseltilmesi; verilere göre filtrelenmesine, yüzey pürüzlülük parametrelerinin hesaplanmasına, ekranda gösterilmesine ve çıktısının alınmasına dayanır. Dokunmatik ölçüm cihazlarında, iğne ucun yüzeyle temasından dolayı küresel geometrilerde doğru sonuçların alınması çoğu kez mümkün olamamaktadır. Yüzeyde optik olarak yapılan ölçme işlemleri ise bu yanlışlıkları ortadan kaldıracaktır. ${ }^{16}$ Bu nedenle çalışmadaki örnekler hazırlanırken dişlerin prepare edilen yüzeylerinin yer düzlemine paralel olacak şekilde düz bir yüzey şeklinde olmasına özen gösterilmiştir.

Yüzey pürüzlülüğü ölçümleri yapılırken farklı yüzey ölçüm parametreleri kullanılmaktadır. Yüzey pürüzlülüğü ölçümü yapılan önceki çalışmalarda sadece $\mathrm{Ra}$ (aritmetik ortalama pürüzlülük) parametresini kullanan araştırmacıların ${ }^{17}$ yanı sıra bu verileri $\mathrm{Rq}(\mathrm{Ra}$ 
değerlerinin karekök ortalaması), Ry (maksimum profil yüksekliği), Rz (yüzey pürüzlülük profilinin en yüksek ve en düşük noktaları arasındaki dikey mesafe) gibi ilave yüzey ölçüm parametreleriyle destekleyen araştırmacılar ${ }^{18,19}$ da bulunmaktadır. Bu in vitro çalışmada da daha detaylı yüzey pürüzlülük verilerine ulaşabilmek için $R a$ verilerinin yanı sıra $R z$ verileri de kaydedilerek, istatiksel olarak değerlendirilmiştir.

Ayad ve ark. yaptıkları çalışmalarında döner aletlerle birlikte kullanılan elmas, tungsten karbid kesim frezleri ve tungsten karbid bitirme frezlerinin diş yüzeyinde oluşturduğu yüzey pürüzlülüğünü değerlendirmişlerdir. Araştırmacıların çalışmalarında istatistiksel bir değer sayılabilecek Ra değerleri göz önüne alındığında elmas frezlerin diş yüzeyinde oluşturdukları yüzey pürüzlülük değeri $(6.8 \pm 0.9 \mu \mathrm{m})$ çalışmamızda da elmas frezlerin diş yüzeyinde oluşturduğu pürüzlülük sonuçlarıyla $(6.07 \pm 1.2$ $\mu \mathrm{m})$ yakınlık göstermektedir. ${ }^{18}$ Ancak aynı araştırmacıların kullandıkları elmas frezlerin oluşturduğu pürüzlülüğün $\mathrm{Rz}$ değerleri $16.4 \pm 2.6 \mu \mathrm{m}$ iken çalışmamızda bu değer aynı tip frezler için $31.9 \pm 6.5 \mu \mathrm{m}$ olarak bulunmuştur. Bu sonuç çalışmamızda kullanılan elmas frezlerle diş yüzeyinde oluşan en yüksek nokta ve en çukur nokta arasındaki dikey mesafe farkının daha fazla olduğunu göstermektedir.

Laufer ve ark. yaptıkları in vitro çalışmalarında dişlerin basamak bölgesindeki yüzey pürüzlülüğünü döner aletler, el aletleri ve ultrasonik cihazlar kullanarak değerlendirmişlerdir. Ancak araştırmacılar çalışmalarında sadece $\mathrm{Ra}$ verilerini göz önüne alarak sonuçları değerlendirmişlerdir. Buna bağlı olarak sadece elmas frezle prepare edilen dentin yüzeyinin yüzey pürüzlülüğü, elmas frezle prepare edildikten sonra sonik enerjiyle çalışan özel uçlarla düzeltilen dentin yüzeyinden istatiksel olarak daha yüksek bulunmuştur. ${ }^{17} \mathrm{Ra}$ değerleri göz önüne alındığında bu sonuç çalışmamızın sonuçlarına da uygunluk göstermektedir. Ancak çalışmamızda bu iki grup arasında $R z$ değerleri dikkate alındığında istatiksel olarak anlamlı farklılık bulunmamıştır. Bu sonuç her iki grupta da dentin yüzeyinde oluşan en çukur nokta ve en yüksek nokta arasındaki dikey mesafe miktarının istatiksel olarak farkllık göstermediğini belirtmektedir. Bu durum bize yüzey pürüzlülüğü değerlendirilirken Ra dışında diğer parametrelerin de kullanımının daha ayrıntılı sonuçlara ulaşabilmeyi sağladığını göstermektedir.

Dişin preparasyonunda özellikle de basamak bölgesinde yüzeyi olabildiğince pürüzsüz hale getirebilmek için birçok frez imalatçı firması değişik dizaynlarda ve farklı gren boyutlarında bitirme frezleri adını verdikleri frezler üretmişlerdir. Ancak Hirata ve ark. yaptıkları çalışmalarında saat yönünün tersi yönde dönen aletlerle bu tip çok ince grenli hatta grensiz özel basamak bitirme frezleriyle prepare edilen dentin yüzeyinin pürüzlülüğünün, tek yönlü olarak titreşimle çalışan bitirme frezleriyle prepare edilen dentinin yüzey pürüzlülüğünden istatiksel olarak daha yüksek olarak bulmuşlardır. ${ }^{19}$

\section{SONUÇ}

Sonuç olarak yapılan bu in vitro çalışmada, ortalama yüzey pürüzlülük değerleri $(R a)$ göz önüne alındığında sonik enerjiyle çalışan özel uçlarla oluşturulan yüzeyin pürüzlülüğü istatistiksel olarak daha düşük bulunmuştur. Yani ultrasonik aletlerin kullanımı ortalama yüzey pürüzlüğünü azaltmışıır. Ancak ortalama $R z$ yani yüzeyde oluşan en yüksek ve en derin noktalar arasındaki dikey mesafe miktarı göz önüne alındığında ise sonik enerjiyle çalışan özel uçların kullanımı ile döner aletlerle elmas frezlerle kullanımı arasında istatistiksel olarak anlamlı bir farklıık bulunmamıştır. Bu durumda çalışmada kullanılan iki farklı tipteki enstrumanların yüzeyde oluşturduğu en girintili ve en çıkıntı noktaların yükseklikleri arasında belirgin bir farklılık bulunmamıştır. 


\section{KAYNAKLAR}

1. Hugo B, Stassinakis A. Preparation and restoration of small interproksimal carious lesions with sonic instrument. Pract Periodont Aesthet Dent 1998; 10: 353-9.

2. Koczarski MJ, Mitchell AL. Direct inlay restorations: utilization of sonic preparation technology in conjunction with ceramic inserts. Pract Periodont Aesthet Dent 1999; 11: 67-73.

3. Massironi D, Pascetta R, Romeo G. Precision in dental esthetics: clinical and laboratory procedures. Milan: Quintessenza Edizioni; 2007, pp.151-73.

4. Ottl P, Lauer HC. Temperature response in the pulpal chamber during ultrahigh-speed tooth preparation with diamond burs of different grit. J Prosthet Dent 1998; 80: 12-9.

5. Evans $C D$, Wilson PR. The effects of tooth preparation on pressure measured in the pulp chamber: a laboratory study. Int J Prosthodont 1999; 12: 439-43.

6. Vanderlei AD, Borges AL, Cavalcanti BN, Rode SM. Ultrasonic versus high-speed cavity preparation: analysis of increases in pulpal temperature and time to complete preparation. J Prosthet Dent 2008; 100: 107-9.

7. Tan K, Pjetursson BE, Lang NP, Chan ES. A systematic review of the survival and complication rates of fixed partial dentures (FPDs) after an observation period of at least 5 years. Clin Oral Implants Res 2004; 15: 654-66.

8. Ferrari M, Dalloca L, Kugel G, Bertelli E. An evaluation of the effect of the adhesive luting on microleakage of the IPS Empress crowns. Pract Periodontics Aesthet Dent 1994; 6: 15-23.

9. Toman M, Toksavul S, Artunç C, Türkün M, Schmage $P$, Nergiz I. Influence of luting agent on the microleakage of all-ceramic crowns. J Adhes Dent 2007; 9: 39-47.

10. Magne $\mathrm{P}$, Belser $\mathrm{U}$. Bonded porcelain restorations in the anterior dentition: a biomimetic approach, Digitized edition, Quintessence Publishing Company. 2002.

11. Blatz MB, Sadan A, Kern M. Resin-ceramic bonding: a review of literature. J Prosthet Dent 2003; 89: 26874.

12. Roulet JF. Degradation of Dental Polymers 1987: Karger Publications, Basel; New York.

13. Rueggeberg FA, Margeson DH. The effect of oxygen inhibition on anunfilled/filled composite system. J Dent Res 1990; 69: 1652-8.

14.Al-Omari WM, Mitchell CA, Cunningham JL. Surface roughness and wettability of enamel and dentin surfaces prepared with different dental burs. J Oral Rehabil 2001; 28: 645-50.

15.Barros JS, Myaki SI, Nör JE, Peters MC. Effect of bur type and conditioning on the surface and interface of dentine. J Oral Rehabil 2005; 32: 849-56.
16. Demircioğlu P. Talaşlı imalat yöntemleriyle imal edilen iş parçalarında yüzey pürüzlülüğünün yüksek hassasiyette iğne uçlu ve 3D optic ölçüm sistemleriyle değerlendirilmesi. Mühendis ve Makina 2011; 52: 81-91.

17.Laufer BZ, Pilo R, Cardash HS. Surface roughness of tooth shoulder preparations created by rotary instrumentation, hand planning, and ultrasonic oscillation. J Prosthet Dent 1996; 75: 4-8.

18.Ayad MF, Rosenstiel SF, Hassan MM. Surface roughness of dentin after tooth preparation with different rotary instrumentation. J Prosthet Dent 1996; 75: 122-8.

19. Hirata T, Nakamura T, Wakabayashi K, Yatani H. Study of surface roughness and marginal fit using a newly developed microfinishing bur and new preparation technique. Int $\mathrm{J}$ Microdent 2009; 1: 61-4.

20.Shillingburg HT, Hobo S, Whitsett LD, Jacobi R, Brackett SE. Fundamentals of fixed prosthodontics. 3rd edn. Canada: Quintessence Publishing Company, 1997.

21.Price RB, Sutow EJ. Micrographic and profilometric evaluation of the finished produced by diamond and tungsten carbide finishing burs on enamel and dentin. J Prosthet Dent 1988; 60: 311-6.

22. Soares CJ, Pizi EC, Fonseca RB, Martins LR. Influence of root embedment material and periodontal ligament simulation on fracture resistance tests. Braz Oral Res 2005; 19: 11-6.

23. Rosentritt M, Furer $C$, Behr M, Lang R, Handel G. Comparison of in vitro fracture strength of metallic and tooth-coloured posts and cores. $J$ Oral Rehabil 2000; 27: 595-601.

24.Wahle JJ, Wendt SL Jr. Dentinal surface roughness: a comparison of tooth preparation techniques. J Prosthet Dent 1993; 69: 160-4.

25. Horne P, Bennani V, Chandler N, Purton D. Ultrasonic Margin Preparation for Fixed Prosthodontics: A Pilot Study. J Eshet Restor Dent 2012; 24: 201-10.

Yazışma Adresi:

Dr. Ece TAMAÇ

Ege Üniversitesi Diş Hekimliği Fakültesi

Protetik Diş Tedavisi AD

35100, Borvnova, İzmir, Türkiye

Tel : $\quad+902323880327$

Faks : +902323880325

E Posta: etamac@yahoo.com 